\title{
DNA Methylation in Genomes of Several Annual Herbaceous and Woody Perennial Plants of Varying Ploidy as Detected by MSAP
}

\author{
Ai Li • Bao-Quan Hu - Zhen-Yi Xue • Li Chen • \\ Wei-Xing Wang • Wen-Qin Song • Cheng-Bin Chen • \\ Chun-Guo Wang
}

Published online: 13 January 2011

(C) The Author(s) 2011. This article is published with open access at Springerlink.com

\begin{abstract}
Polyploidization is known to accompany altered DNA methylation in higher plants, which plays an important role in gene expression regulation and maintaining genome stability. While the characteristics of DNA methylation in different polyploid plants are still to be elucidated; here, status of genomic DNA methylation in a series of diploid, triploid, and tetraploid annual herbaceous plants (watermelon and Salvia) and woody perennials (pear, Poplar, and loquat) were explored by methylation-specific amplified polymorphism analysis. The results indicated that levels of DNA methylation in triploid watermelon and Salvia were lower than their diploid parents. In triploid Poplar and pear, higher levels of DNA methylation were detected, and no significant difference was observed between triploid and tetraploid in all tested materials. Further data analysis suggested that about half of the total detected sites underwent changes of DNA methylation patterns in triploid watermelons and Salvia, as well as an obvious trend towards demethylation. However, the changes of DNA methylation patterns in three triploid woody perennials were only $17.54-33.40 \%$. This implied that the characteristics of DNA methylation are significant-
\end{abstract}

A. Li • B.-Q. Hu • Z.-Y. Xue $\cdot$ L. Chen · W.-Q. Song •

C.-B. Chen $(\square) \cdot$ C.-G. Wang $(\square)$

College of Life Sciences, Nankai University,

Tianjin 300071, People's Republic of China

e-mail: Chencb@nankai.edu.cn

C.-G. Wang

e-mail: wangcg@nankai.edu.cn

W.-X. Wang

College of Horticulture and Landscape, Xi Nan University,

Chongqing 400716, People's Republic of China ly different during the polyploidization of different plant species. Furthermore, the results suggested that the level of DNA methylation was nonlinearly related to the ploidy level, and triploid plants displayed more interesting DNA methylation status. The characteristics and possible functions of DNA methylation in different ploidy series are further discussed.

Keywords DNA methylation · MSAP Annual herbaceous plants $\cdot$ Woody perennial $\cdot$ Polyploidization

\author{
Abbreviations \\ MSAP Methylation-sensitive amplification \\ polymorphism \\ PCR Polymerase chain reaction
}

\section{Introduction}

The duplication of genomes (polyploidy), either of the same genome (autopolyploidy) or of diverged genomes (allopolyploidy or amphiploidy), is a major force of evolution. In plants, it is estimated that polyploidy occurred in $50-70 \%$ of flowering species (Masterson 1994), and most of them have undergone one or more polyploidization events during their evolution (Spring 1997; Wolfe and Shields 1997). Some very important crops, such as maize (Gaut and Doebley 1997), soybean (Shoemaker et al. 1996), and Brassica (Lagercrantz and Lydiate 1996) are of polyploid origin. Genome sequencing data provides further evidence for polyploidy, although Arabidopsis has a smaller genome, it is also an ancient tetraploid (Blanc et al. 2000). After polyploidization, plants were usually shown to 
obviously increase the capabilities of adapting to their environment or possess traits that are desirable for domesticated crops such as increased abiotic and biotic stress tolerance, early flowering time, increased organ size, and biomass (Hilu 1993; Liu and Wendel 2002). Consequently, polyploidization has not only been regarded as one of the most important driving forces for plant genome evolution and speciation, but also makes an enormous contribution to agriculture. Recent investigations have identified that polyploidization events can result in rapid genetic changes in the genome structure (Swapna et al. 2010; Song et al. 1995; Pires et al. 2004; Pontes et al. 2004,) or gene expression profiles ( $\mathrm{Lu}$ et al. 2006; Adams et al. 2003; Kashkush et al. 2002; Adams et al. 2004). Moreover, beyond variation at the DNA sequence level, DNA methylation, as one method of primary epigenetic regulation, was also identified to play an important role in the formation of polyploids (Levy and Feldman 2004; Lee and Chen 2001; Liu and Wendel 2003; Wang et al. 2004). Characteristics of DNA methylation in the polyploidization of Arabidopsis (Madlung et al. 2002), wheat (Shaked et al. 2001; Han et al. 2003), rice (Zhang et al. 2006), cotton (Keyte et al. 2006), and Cucumis (Chen and Chen 2008) revealed that the rapid adjustments of DNA methylation levels and patterns occurred. However, most investigations about DNA methylation and polyploidization were focused on the annual herbaceous plants as mentioned polyploid Arabidopsis, wheat, cotton, rice, and Brassica (Madlung et al. 2002; Zhang et al. 2006; Chen and Chen 2008). In contrast, relatively few attentions have been dedicated to elucidating the relationship between DNA methylation and polyploidization in woody perennials such as Poplar, pear, probably due to their large-size genomes, long growth cycles, and complex genetic backgrounds, and further to elucidating the different characteristics of DNA methylation between the annual herbaceous plants and woody perennials. In the present study, three ploidy series of woody perennials, in addition to two ploidy series of annual herbaceous plants were used as the samples. Analysis of the DNA methylation status was carried out. Consequently, the aim of this work was to provide an insight into the characteristics of DNA methylation in the polyploidization of certain annual herbaceous plants and woody perennials, and the relationship between the level of DNA methylation and the ploidy level.

\section{Materials and Methods}

\section{Plant Materials}

The materials for this study included five different combinations of triploids with their corresponding diploid and/or tetraploid parents. The first cross involved diploid $(2 \times)$ watermelon (Citrulluis vulgaris Schrad.) $\times$ tetraploid $(4 \times)$ watermelon. The second cross involved diploid $(2 \times)$ Salvia (Salvia miltiorrhiza Bunge) $\times$ tetraploid $(4 \times)$ Salvia . The third cross involved diploid $(2 \times)$ pear (Pyrus $\times$ bretschneideri Rehd.cv. "Yali") $\times$ tetraploid $(4 \times)$ pear. The forth cross involved diploid $(2 \times)$ loquat (Eriobotrya japonica Lindl.) $\times$ tetraploid $(4 \times)$ loquat. The fifth combination involved diploid ( $2 \times)$ Poplar (Poplar Latin), and newly synthesized triploid $(3 \times)$ Poplar, which was created by pollen doubling. The tetraploids of watermelon, Salvia, and loquat were obtained after colchicine treatment of the diploid plants, while the tetraploid pear was created by bud mutation of diploid. All triploids, except triploid Poplar, were generated by crossing diploid with tetraploid as the female recipient of pollen.

\section{DNA Isolation}

The ploidy levels of all materials were determined by counting chromosome numbers in root cells using the squash technique as described previously (Urdampilleta et al. 2006). Genomic DNA was isolated from young fresh leaves of different ploidy plants by the cetyltrimethylammonium bromide method (Murray and Thompson 1980) with some modifications. DNA was dissolved in 50- $\mu \mathrm{l} \mathrm{TE}$ (pH 8.0) after treatment with RNase. Finally, the concentration and purity of DNA sample was measured by absorbance and the ratio of $\mathrm{OD}_{260} / \mathrm{OD}_{280}$, using NanoDrop ${ }^{\circledR}$ ND-1000 (Nanodrop Technologies, USA).

\section{Digestion and Ligation Reactions}

DNA samples were separately digested with EcoRI (promega, USA) + HpaII (promega, USA) and EcoRI + MspI (promega, USA), of which HpaII and MspI are isoschizomers. They can recognize and digest the same site (5'-CCGG-3'), but display differential sensitivity to DNA methylation. HpaII is inactive if either cytosine is fully methylated (methylation of both strands), while it can cleave the hemi-methylated sequence (only one strand methylation). MspI is sensitive only to methylation at the external cytosine. It cuts in the case of inner cytosine methylation (CmCGG), but not in the case of outer cytosine methylation (mCCGG). Therefore, in methylation-sensitive amplification polymorphism (MSAP) analysis, different polymorphic bands from polymerase chain reaction (PCR) amplification can reflect the DNA methylation status. Here, the digestion reaction was performed in a volume of $15 \mu \mathrm{l}$ containing 400 ng DNA template, $3 \mathrm{U}$ EcoRI, $3 \mathrm{U}$ HpaII (or $M s p \mathrm{I}$ ), and $3 \mu \mathrm{l} 5 \times$ ligase-digestion buffer $(0.05 \mathrm{M}$ Tris$\mathrm{HCl}, 0.05 \mathrm{M} \mathrm{MgAc} 2,0.25 \mathrm{M} \mathrm{KAc})$. The mixture was incubated at $37^{\circ} \mathrm{C}$ for $24 \mathrm{~h}$. After that, the digested 
fragments were ligated to the adapters in a buffer containing 0.8 U T4 DNA ligase (TaKaRa, Japan), 30 pM EcoRI adapter (Table 1), 30 pM HpaII or MspI adapter (Table 1), $0.4 \mathrm{mM}$ ATP, and $1 \mu \mathrm{l} 5 \times$ ligase digestion buffer in a final volume of $20 \mu \mathrm{l}$. The mixture was incubated at $16^{\circ} \mathrm{C}$ overnight, inactivated at $65^{\circ} \mathrm{C}$ for $10 \mathrm{~min}$, and stored at $-20^{\circ} \mathrm{C}$.

Preamplification and Selective Amplification

Two amplification processes were carried out according to amplified fragment length polymorphism procedure (Portis et al. 2004), respectively. Preamplified PCR reactions were performed in a final volume of $25 \mu$ l containing $5 \mu$ l of diluted ligation products, $0.4 \mu \mathrm{M}$ of $E_{00}$ and $H / M_{00}$ preamplification primer (Table 1), $0.5 \mathrm{U}$ of Taq polymerase (TaKaRa, Japan), $200 \mu \mathrm{M}$ of dNTPs (TaKaRa, Japan), and $2.5 \mu \mathrm{l}$ of $10 \times \mathrm{PCR}$ buffer. The DNA fragments were amplified for 25 cycles of $94^{\circ} \mathrm{C}$ for $30 \mathrm{~s}, 56^{\circ} \mathrm{C}$ for $1 \mathrm{~min}$, and $72^{\circ} \mathrm{C}$ for $1 \mathrm{~min}$, as described by Xiong and $\mathrm{Xu}$ (1999) with some modifications. Following that the preamplification product was diluted 1:10 $(v / v)$ with $\mathrm{ddH}_{2} \mathrm{O}$, and $1 \mu \mathrm{l}$ of these diluted samples was mixed with $2 \mu$ of $10 \times$ PCR buffer, $0.3 \mu \mathrm{M}$ of EcoRI and HpaII/MspI selective amplification primers (Table 1), $0.5 \mathrm{U}$ of Taq polymerase (TaKaRa, Japan), and $200 \mu \mathrm{M}$ of dNTPs (TaKaRa, Japan) in a final volume of $20 \mu \mathrm{l}$. The PCR conditions were as follows: 13 cycles at $94^{\circ} \mathrm{C}$ for $30 \mathrm{~s}, 65^{\circ} \mathrm{C}$ for $30 \mathrm{~s}$ (reduced by $0.7^{\circ} \mathrm{C}$ each cycle), $72^{\circ} \mathrm{C}$ for $1 \mathrm{~min}, 23$ cycles at $94^{\circ} \mathrm{C}$ for $30 \mathrm{~s}, 56^{\circ} \mathrm{C}$ for $30 \mathrm{~s}$, and $72^{\circ} \mathrm{C}$ for $1 \mathrm{~min}$.

\section{Denaturing Polyacrylamide Gel and Data Analysis}

Of the selective amplified products, $2.5 \mu \mathrm{l}$, mixed 1:1 $(\mathrm{v} / \mathrm{v})$ with a loading buffer, were heated at $100^{\circ} \mathrm{C}$ for $10 \mathrm{~min}$ and quickly chilled on ice for $2 \mathrm{~min}$. The entire mixture was loaded onto $6 \%$ denaturing polyacrylamide gels. Electro- phoresis was performed at a constant power of $35 \mathrm{~W}$ for $2 \mathrm{~h}$. After silver staining, statistical analysis was carried out. Only clear and reproducible bands that appeared in three independent PCR amplifications (staring from the digestion-ligation step, i.e., the first step of MSAP) were scored and further transformed into a binary character matrix, where " 1 " indicated the presence and " 0 " showed the absence of a band. Following that, the formula as described by Zhao et al. (2007) were used to elucidate the differences between triploid and diploid or tetraploid of each ploidy series. In this formula, $n_{1}$ represents the total sites of diploid or tetraploid; $n_{2}$ represents the total sites of triploid;

$$
\begin{aligned}
p & =\frac{y_{1}+y_{2}}{n_{1}+n_{2}}, \quad q=1-p, \quad \sigma_{p_{1}}-p_{2} \\
& =\sqrt{p q\left(\frac{1}{n_{1}}+\frac{1}{n_{2}}\right)}, \quad U=\frac{p_{1}-p_{2}}{\sigma_{p 1-p 2}}
\end{aligned}
$$

$y_{1}$ represents the total DNA methylation sites, hemimethylation sites, or fully methylation sites of diploid or tetraploid; $y_{2}$ shows the total DNA methylation sites, hemimethylation sites, or fully methylation sites of triploid; $p_{1}$ is the percentage of total methylation sites, hemimethylation sites, or fully methylation sites of diploid or tetraploid; and $p_{2}$ is the percentage of total methylation sites, hemimethylation sites, or fully methylation sites of triploid.

\section{Results}

Validation of the Ploidy Level by Chromosome Counting

All materials used in the present study were determined by counting chromosome numbers in root cells for their ploidy levels. The results indicated that in each cell, the corresponding chromosome numbers were correct as

\begin{tabular}{|c|c|c|}
\hline & EcoRI (E) 5'-3' & $H p a \mathrm{II} / M s p \mathrm{I}(\mathrm{H} / \mathrm{M}) 5^{\prime}-3^{\prime}$ \\
\hline Adapter-1 & CTCGTAGACTGCGTACC & GACGATGAGTCTAGAA \\
\hline Adapter-2 & AATTGGTACGCAGTC & CGTTCTAGACTCATC \\
\hline \multirow[t]{5}{*}{ Pre-amplification primers } & GACTGCGTACCAATTC $\left(\mathrm{E}_{00}\right)$ & GATGAGTCTAGAACGG $\left(\mathrm{H} \mathrm{M}_{00}\right)$ \\
\hline & & GATGAGTCTAGAACGGCA(H $\left(\mathrm{H}_{15}\right)$ \\
\hline & GACTGCGTACCAATTAAC $\left(\mathrm{E}_{32}\right)$ & GATGAGTCTAGAACGGCT( $\left.\mathrm{H}_{18}\right)$ \\
\hline & GACTGCGTACCAATTACA $\left(\mathrm{E}_{35}\right)$ & GATGAGTCTAGAACGGGA(H $\left.{ }_{19}\right)$ \\
\hline & GACTGCGTACCAATTACG $\left(\mathrm{E}_{37}\right)$ & GATGAGTCTAGAACGGGT( $\left.\mathrm{H}_{22}\right)$ \\
\hline \multirow[t]{4}{*}{ Selective amplification primers } & GACTGCGTACCAATTAGC(E $\left(\mathrm{E}_{39}\right)$ & GATGAGTCTAGAACGGTG $\left(\mathrm{H}_{25}\right)$ \\
\hline & 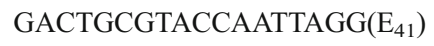 & GATGAGTCTAGAACGGCAA $\left(\mathrm{H}_{47}\right)$ \\
\hline & GACTGCGTACCAATTCAA $\left(\mathrm{E}_{47}\right)$ & GATGAGTCTAGAACGGCAT $\left(\mathrm{H}_{50}\right)$ \\
\hline & GACTGCGTACCAATTCAT $\left(\mathrm{E}_{50}\right)$ & GATGAGTCTAGAACGGCTA $\left(\mathrm{H}_{59}\right)$ \\
\hline
\end{tabular}

Table 1 Sequences of adapters and pre-selective amplification primers used for MSAP analysis 
anticipated, implying that all materials were stable with respect to ploidy level (Fig. 1). Further karyotypic analysis indicated that no obvious chromosome deletion events occurred in any materials.

DNA Methylation Level of the Same Plants but with Different Ploidy Level

Fifty-six pairs of selective primers were used to analyze the DNA methylation status of watermelon, Salvia, pear, Poplar, and loquat polyploidy series, respectively. The data indicated that in the two annual herbaceous plants, the DNA methylation level of diploid, triploid, and

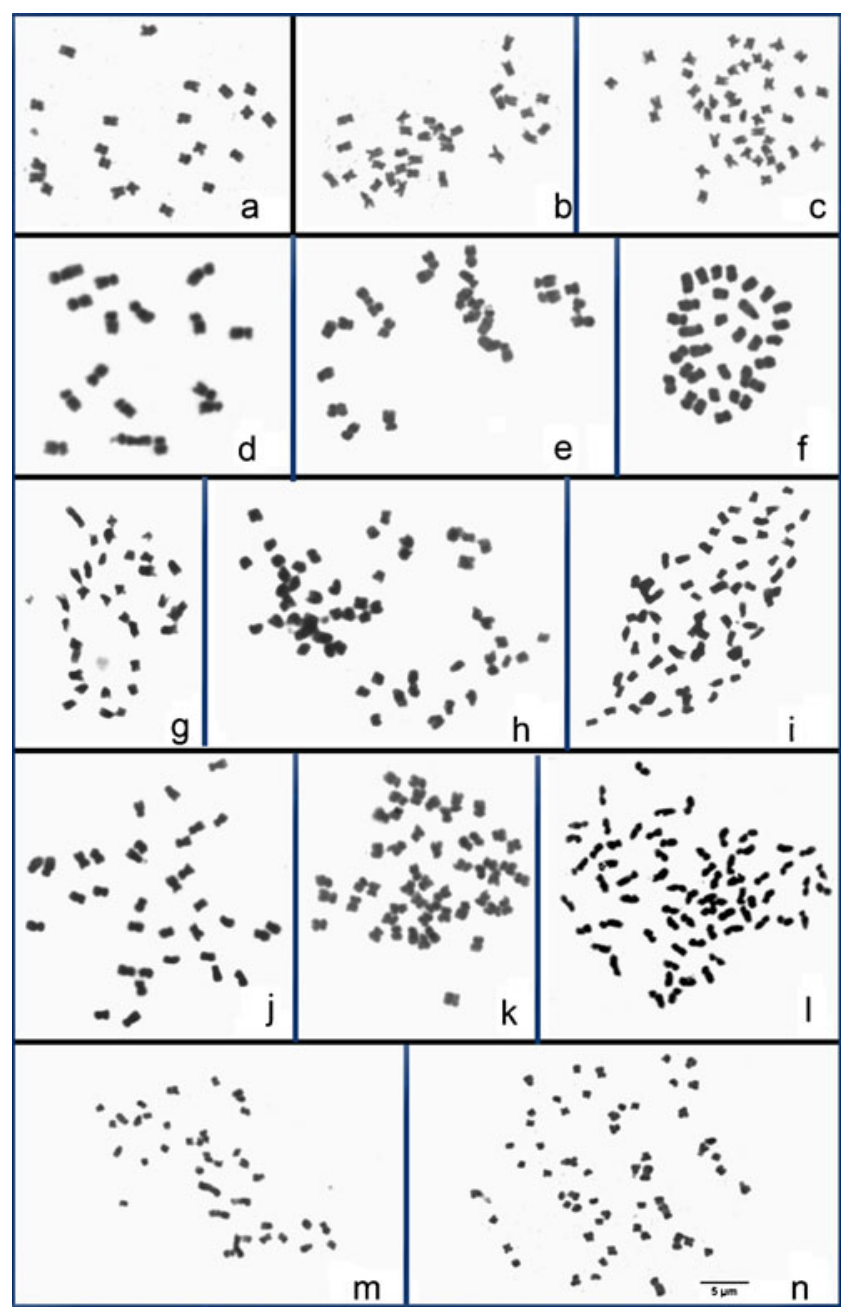

Fig. 1 Chromosome analysis of watermelon, Salvia miltiorrhiza, pear, loquat, and Poplar. a Diploid watermelon $(2 n=2 \times=22)$, b triploid watermelon $(2 n=3 \times=33)$, c tetraploid watermelon $(2 n=4 \times=$ $44)$, d diploid Salvia $(2 n=2 \times=16)$, e triploid Salvia $(2 n=3 \times=24)$, f tetraploid Salvia $(2 n=4 \times=32), \mathbf{g}$ diploid pear $(2 n=2 \times=30)$, h triploid pear $(2 n=3 \times=45)$, i tetraploid pear $(2 n=4 \times=60)$, j diploid loquat $(2 n=$ $2 \times=34)$, $\mathbf{k}$ triploid loquat $(2 n=3 \times=51)$, I tetraploid loquat $(2 n=4 \times=68)$, m diploid Poplar $(2 n=2 \times=38)$, and $\mathbf{n}$ triploid Poplar $(2 n=3 \times=57)$; scale bar $5 \mu \mathrm{m}$ tetraploid watermelon was $28.00 \%, 22.90 \%$, and $27.37 \%$, respectively, and the corresponding value of different ploidy Salvia was $43.66 \%, 38.87 \%$, and $39.79 \%$, respectively (Table 2). In the two woody perennials, pear and loquat, the DNA methylation level of each ploidy level was distinctly lower than the corresponding value of watermelon and Salvia, and the DNA methylation level of diploid and triploid Poplar was $16.10 \%$ and $24.11 \%$, respectively (Table 2, Fig. 2). Further statistical analysis indicated that the total levels of DNA methylation of triploid watermelon and Salvia were significantly lower than those of their diploid parents ( $U$ values ranged from 2.00 to 2.11 and $U_{0.05}=1.96$ ). Similarly, the value also showed a degressive trend corresponding to the tetraploid parents, although this did not reach a statistically significant level ( $U$ values ranged from 0.40 to 1.79 and $U_{0.05}=$ 1.96). In contrast, the total level of DNA methylation of triploid pear and Poplar showed significantly higher values than those of their diploid parents ( $U$ values ranged from 2.41 to 5.72 and $U_{0.05}=1.96$ ). While the DNA methylation level of triploid loquat showed no significant difference compared to its diploid parent ( $U$ value was 1.04 and $U_{0.05}=1.96$ ).

DNA Methylation Patterns of the Same Plants but with Different Ploidy Level

Based on the polymorphic bands detected by MSAP, the DNA methylation patterns in each ploidy series of watermelon, Salvia, pear, Poplar, and loquat all could be categorized into four groups (group A, B, C, and D; Fig. 3), of which type D corresponded to patterns that were undecided by the present method, which accounted for less than $2 \%$ of all tested sites in the present data. This was not shown and considered in the subsequent assays. When pair-wise comparisons between triploid plants and their diploid or tetraploid parents were carried out according to the hypermethylation and demethylation ratio of triploid plants, the five ploidy series materials could be categorized into three types. One type including the annual herbaceous plants watermelon and Salvia showed an obvious trend of demethylation ( $U$ values ranged from 1.28 to 11.48 and $U_{0.05}=1.96$ ). In the second type, including two woody perennials pear and Poplar, no significant differences between the hypermethylation and demethylation ratios were detected ( $U$ values ranged from 0.50 to 1.00 and $U_{0.05}=1.96$ ). Interestingly, the third type was only associated with loquat, and although this was also regarded as a woody perennial, the character of DNA methylation patterns in triploid loquat was not similar to those of triploid pear and Poplar. Moreover, it is also not consistent with those of triploid watermelon or Salvia (Table 3). 


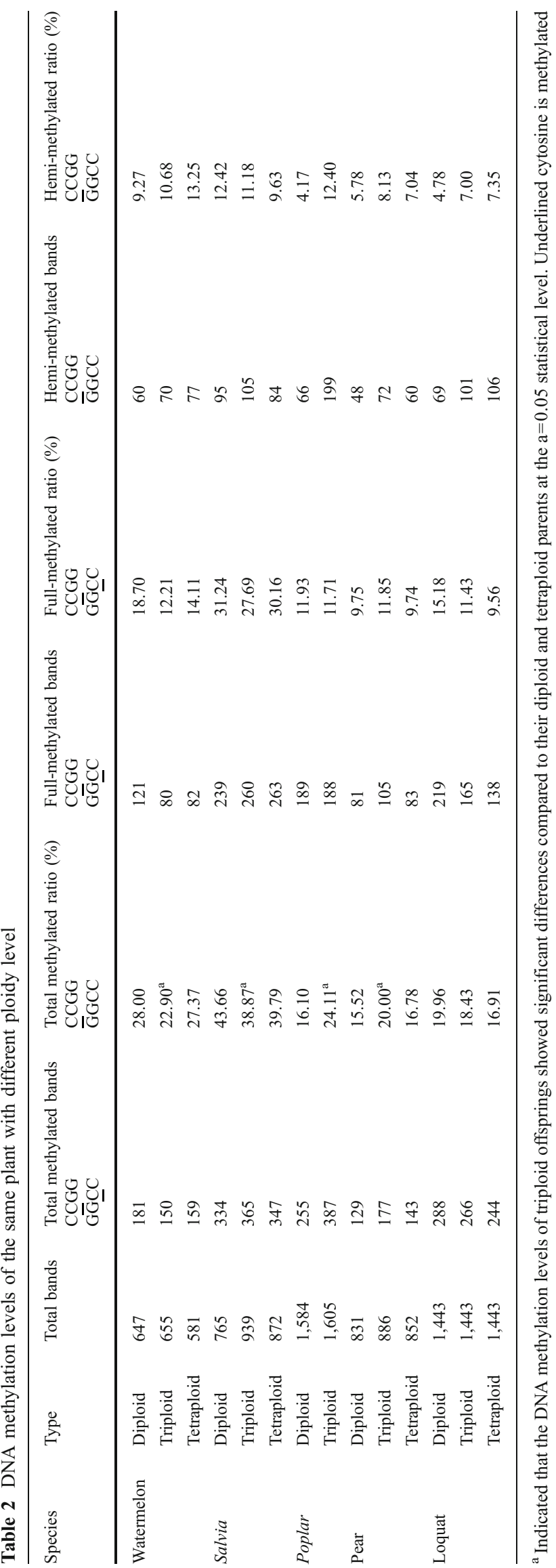

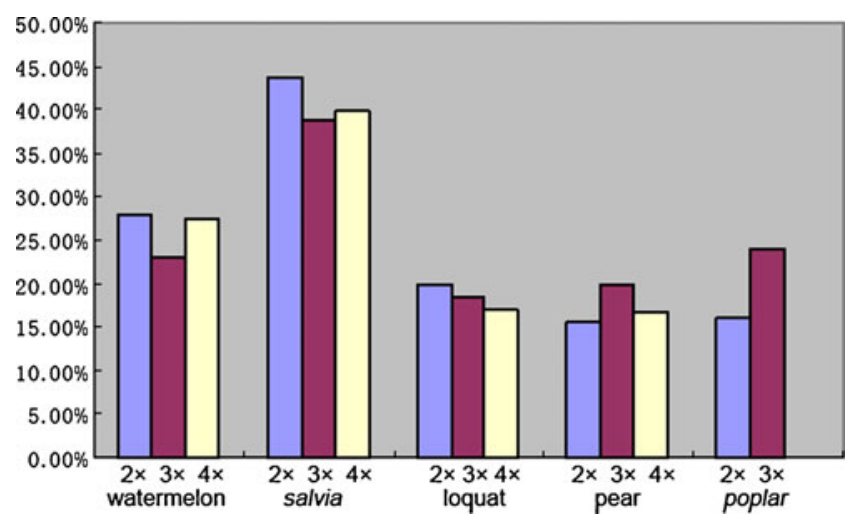

Fig. 2 Total DNA methylation levels of different ploidy watermelon, Salvia, loquat, pear and Poplar. $2 \times, 3 \times, 4 \times$ indicated diploid, triploid, tetraploid, respectively

DNA Methylation Level of Different Plants with the Same Ploidy Level

The DNA methylation levels of samples of watermelon, Salvia, pear, Poplar, and loquat with the same ploidy level were also analyzed (Fig. 4). The data indicated that the DNA methylation level in five diploid materials was varied from $15.52 \%$ to $43.66 \%$, of which diploid Salvia showed the highest DNA methylation level, following by the DNA methylation level of diploid watermelon. Similar to these five diploid materials, the DNA methylation level in five triploid and four tetraploid materials were also significantly different. The extent of change in triploid materials was from $18.43 \%$ to $38.87 \%$ and from $16.78 \%$ to $39.79 \%$ in tetraploid materials. Moreover, the higher DNA methylation level was also usually detected in Salvia and watermelon (Table 2, Fig. 4). Further statistical analysis identified that for the same ploidy level, the annual herbaceous plants, watermelon and Salvia, always showed significantly higher DNA methylation levels than those of the woody perennials, pear, Poplar, and loquat ( $U$ values ranged from 2.38 to 14.44 and $U_{0.05}=1.96$ ).

DNA Methylation Patterns of Different Plants with Same Ploidy Level

The characteristics of DNA methylation patterns in five different plants with same ploidy level were explored further, especially, the DNA methylation patterns in triploid samples of all plants which were closely connected to the corresponding diploid and/or tetraploid parents. Moreover, triploid plants always show some excellent traits that are not found in diploid, tetraploid, or other polyploid plants. Then a series of comparisons between triploid plants and their corresponding diploid and/or tetraploid parents were conducted. The data 

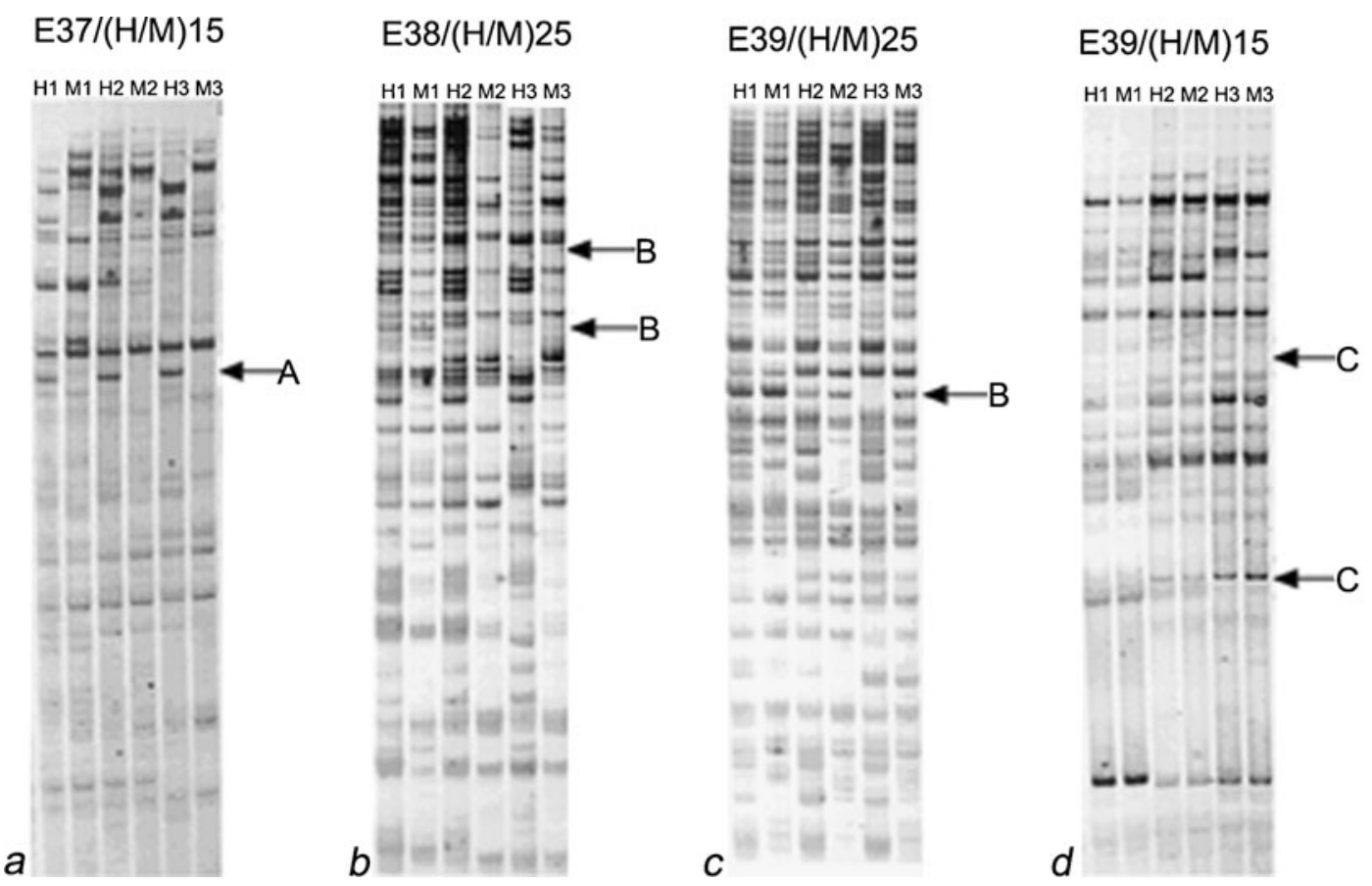

$\mathrm{E} 38 /(\mathrm{H} / \mathrm{M}) 32$

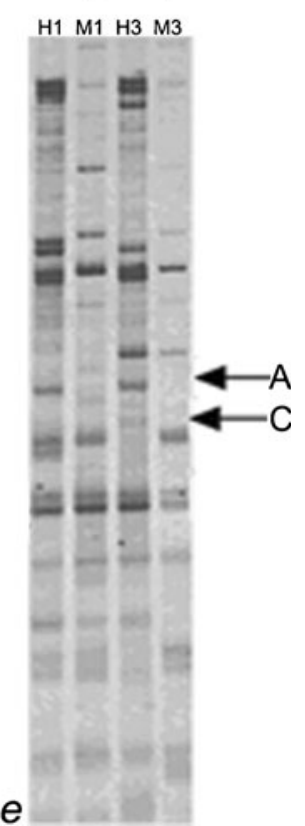

Fig. 3 Example of MSAP profiles showing the three major types of locus-specific DNA methylation patterns in triploid materials relative to their corresponding diploid and/or tetraploid parents. $M 1, M 2, M 3$ genomic DNA was digested with $\mathrm{MspI}$ and EcoRI; H1, H2, H3 genomic DNA was digested with HpaII and EcoRI; 1, 2, 3 triploid, tetraploid, and diploid; a-e watermelon, Salvia, pear, loquat, and Poplar, respectively. $A$ indicated that the DNA methylation patterns were unchanged; $B$ indicated that the demethylation events occurred; $C$ indicated that hypermethylation events occurred distinctly indicated that, in triploid watermelon and Salvia, the DNA methylation patterns of more than $40 \%$ sites were adjusted either compared with the diploid parents or tetraploid parents (Table 3). However, in the triploid Poplar, pear, and loquat the changes of value were less than $34 \%$ (Table 3). It implied that in the formation of polyploids, the adjustments of DNA methylation patterns in the annual herbaceous plants (watermelon and Salvia) were more frequent than those in the woody perennials (Poplar, pear, and loquat).

\section{Discussion}

Increasing numbers of studies have demonstrated that polyploidization is a major driving force for plant genome evolution and speciation (Liu and Wendel 2003; Hegarty and Hiscock 2007; Soltis et al. 2004; Adams and Wendel 2005; Gaut and Doebley 1997; Shoemaker et al. 1996; Lagercrantz and Lydiate 1996; Blanc et al. 2000). However, a consequence of polyploidization is the breakage of cytoplasmic-nuclear balance and the conflict that results

Table 3 Changes of DNA methylation patterns in the comparison of triploid with diploid or tetraploid materials

\begin{tabular}{|c|c|c|c|c|c|c|c|c|c|}
\hline & \multicolumn{2}{|c|}{ Watermelon } & \multicolumn{2}{|l|}{ Salvia } & \multicolumn{2}{|l|}{ Loquat } & \multicolumn{2}{|l|}{ Pear } & \multirow{2}{*}{$\begin{array}{l}\text { Poplar } \\
3 X-2 X\end{array}$} \\
\hline & $3 X-2 X$ & $3 X-4 X$ & $3 X-2 X$ & $3 X-4 X$ & $3 X-2 X$ & $3 X-4 X$ & $3 X-2 X$ & $3 X-4 X$ & \\
\hline Total sites & 735 & 725 & 728 & 569 & 1411 & 1411 & 886 & 878 & 1758 \\
\hline Hypermethylation sites & 143 & 101 & 151 & 101 & 204 & 222 & 77 & 69 & 299 \\
\hline Hypermethylation ratio & $19.50 \%$ & $13.90 \%$ & $20.74 \%$ & $17.75 \%$ & $14.46 \%$ & $15.73 \%$ & $8.69 \%$ & $7.86 \%$ & $17.01 \%$ \\
\hline Demethylation sites & 163 & 228 & 360 & 200 & 243 & 203 & 89 & 85 & 288 \\
\hline Demethylation ratio & $22.10 \%$ & $31.50 \%$ & $49.45 \%$ & $35.15 \%$ & $17.22 \%$ & $14.39 \%$ & $10.05 \%$ & $9.68 \%$ & $16.38 \%$ \\
\hline Total changed sites & 306 & 329 & 511 & 301 & 447 & 425 & 166 & 154 & 587 \\
\hline Total changed ratio & $41.60 \%$ & $45.40 \%$ & $70.20 \%$ & $52.90 \%$ & $31.68 \%$ & $30.12 \%$ & $18.74 \%$ & $17.54 \%$ & $33.40 \%$ \\
\hline
\end{tabular}

" indicated the patterns of DNA methylation at CCGG sites were changed due to hypermethlyation events in $3 \mathrm{X}$ versus $2 \mathrm{X}$ or $4 \mathrm{X}$; " indicated the patterns of DNA methylation at CCGG sites were changed due to demethylation events in $3 \mathrm{X}$ versus $2 \mathrm{X}$ or $4 \mathrm{X}$ 


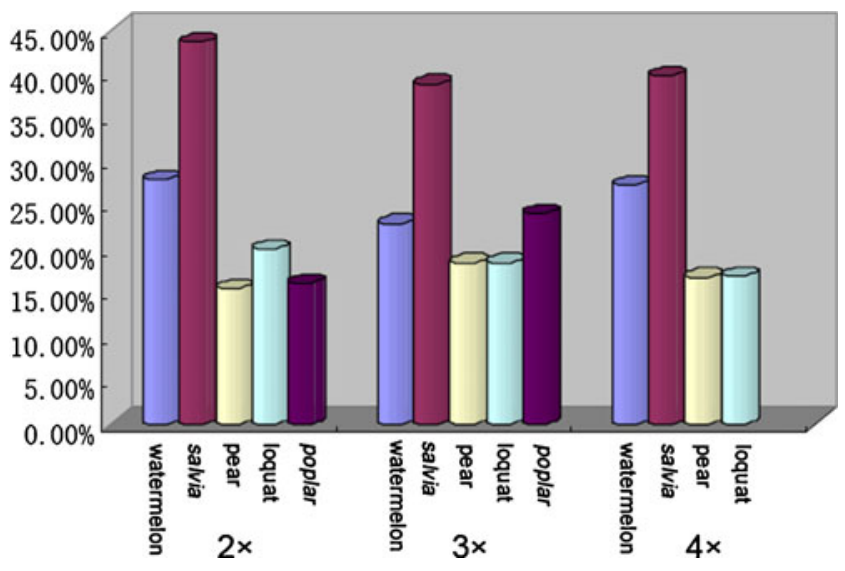

Fig. 4 Total DNA methylation levels of watermelon, Salvia, loquat, pear, and polar with the same ploidy level. $2 \times, 3 \times, 4 \times$ indicated diploid, triploid, and tetraploid, respectively

from two or more divergent and related genomes being brought into a single cell nucleus. The reestablishment of the cytoplasmic-nuclear balance and stabilization of multiple genomes in a single nucleus by polyploidy plants, and the further exhibiting of high applicability to their environment or excellent traits desired by agriculture are interesting areas of further research. A series of evidences revealed that genetic adjustments may occur during polyploidization (Rayburn et al. 2009; Chen 2007; Pires et al. 2004; Udall et al. 2005; Liu and Wendel 2003; Osborn et al. 2003), as well as the epigenetic modifications, such as DNA methylation and histone protein modification, are also important in this process (Fiuk et al. 2010; Demetriou et al. 2010; Lukens et al. 2006; Gaeta et al. 2007; Salmon et al. 2005; Shaked et al. 2001; Liu et al. 2001). In the present study, chromosome deletion was not detected in all samples (Fig. 1), implying the obvious cytogenetic variation did not occur. Moreover, several previous investigations have identified that although the changes of genomic structure, gene expression profiles, or/and quantities occurred in polyploidization, these changes appeared not to be so dramatic, and novel genes produced due to polyploidization were little reported (Albertin et al. 2005; Wang et al. 2006; Stupar et al. 2007). Consequently, genetic adjustments may also occur in the present materials, while they are not regarded as the mean emphasis for exploration. Here, we mainly focused on the characteristics of DNA methylation, which has been widely detected, and identified closely associated with genome stabilization in different polyploid plants (Chen and Chen 2008; Lukens et al. 2006; Madlung et al. 2002). The results clearly revealed that the characteristics of DNA methylation levels and patterns were different between the annual herbaceous plants (watermelon and Salvia) and the woody perennials (Poplar, pear, and loquat) during their polyploidization (Tables 2, 3). The DNA methylation levels of watermelon and Salvia were higher than the same ploidy of woody perennials, Poplar, pear, and loquat (Fig. 4). Moreover, the adjustments of DNA methylation patterns were more frequent in the two annual herbaceous plants than those of three woody perennials (Table 3). According to these observations and the materials used in the present study, a speculation is that these differences may be associated with or caused by the biological characteristics of individual species. As is well known, the annual herbaceous plants, such as watermelon and Salvia, usually complete a life cycle within a short time. This character can make them more sensitive to the changes of themselves and environment. Once polyploidization events occur, to cope with the genomic shock (McClintock 1984) and maintain the cytoplasmic-nuclear balance, large-scale adjustments are required such as changes of DNA methylation. In contrast, some woody perennials such as Poplar and pear undergo a much longer life cycle, and can bear a higher tolerance to changes within themselves and/or environment than the annual herbaceous plants. In this manner, when polyploidization events occur, dramatical genetic adjustments, even epigenetic modification is not necessary. Interestingly, although loquat is also a woody perennial, unlike Poplar and pear, the characteristic of DNA methylation level of triploid loquat is between those of the two annual herbaceous plants (DNA methylation level in triploid watermelon and Salvia was lower than their corresponding diploid parents) and the two woody perennials (DNA methylation level in triploid pear and Poplar was much higher than diploid parents; Table 2, Fig. 2). Further data indicated that the characteristic of DNA methylation pattern adjustments was also between the two annual herbaceous plants and the two woody perennials (Table 3). It may further convince the speculation that characteristic of DNA methylation, as well as other adjustments of genetics and epigenetics in different polyploid plants may be closely related to the biological characteristics of individual species. To a certain degree, the biological characteristics of loquat are similar to the annual herbaceous plants, while it is also distinctly different from the deciduous woody perennials such as the pear and Poplar.

Further data analysis indicated that the levels of DNA methylation were nonlinearly related to the ploidy level in each tested ploidy series materials (Fig. 2). It indicated that the higher ploidy level did not necessarily correspond to higher or lower levels of DNA methylation in different plant species. The similar phenomenon was detected in polyploidizaton of the Spartina species, in which the evolutional characteristic of the Waxy gene also did not show the coherence between the copy number and the ploidy level (Fortune et al. 2007). It fully exhibited the complexity of the natural basis of plant polyploidization. However, the complexity of this process, all genetic and/or 
epigenetic modifications must cope with the changes of nuclear-cytoplasmic ratio and the instability of genomes, two vital events resulted by polyploidization. DNA methylation, as the most prevalent epigenetic modification of plant nuclear DNA, rightly plays a very important role in maintaining transposon inactivation, heterochromatization, and the stability of other repeat sequences (Cuozzo et al. 2007; Martienssen and Colot 2001), all which are closely related to the stability of whole genomes. Consequently, when polyploidizaton event occur, suitable DNA methylation modifications can reduce the degree of incompatibility that arises from two or more genomes in a nucleolus. The present results also suggested that although a nonlinear relationship was observed between the level of DNA methylation and ploidy level, the adjustments of DNA methylation patterns occurred widely at many genomic sites in each of the polyploid plants (Table 3). These results implied that the DNA methylation modifications surely participated in the formation of polyploid plants. However, the mechanisms by which DNA methylation modifications at the whole genomic level or at specific sites affects the stability of genomes during polyploidization still required further investigation. Another important role of DNA methylation is the regulation of gene expression. As is widely described, methylated state usually is associated with inactivation of gene expression and, conversely, gene activation is associated with demethylation (Carvalho et al. 2010; Diéguez et al. 1997; Cao and Jacobsen 2002; Wada et al. 2004; Wang et al. 2004). The methylation, hypermethylation, and demethylation events were widely observed in every ploidy level of five plant species (Table 3). However, the triploids of all materials were the most interesting. Different from tetraploids, triploids as oddploidy polyploids possess certain special characteristics in both DNA methylation levels and patterns. For example, the triploid watermelon and Salvia showed lower DNA methylation levels compared to their diploid parents (Table 2, Fig. 2), and demethylation events were predominant (Table 3). This means that numerous gene expressions were activated or upregulated in triploid watermelon and Salvia, which may be closely associated with the formation of some excellent traits that are usually prominently exhibited in triploid plants, such as seedlessness, increased organ size, and biomass (Hilu 1993; Liu and Wendel 2002). However, similar to two triploid annual herbaceous plants, although three triploid woody perennials, triploid pear, triploid Poplar, and triploid loquat, also possess excellent traits in growth, development, and organ size, as well as previous reported triploid banana, triploid apple, triploid mulberry, and triploid sugarbeet (Hamada 1963; Bhojwani and Razdan 1996; Sreekumari et al. 1999; Thomas et al. 2000). It appears that the characteristics of DNA methylation were not consistent with those in triploid watermelon and Salvia (Tables 2, 3). This implied that the function of DNA methylation modification may be different in the formation of triploidy effect of woody perennials from that in the annual herbaceous plants. Consequently, the underlying mechanism of triploidy effect still needs further elucidation, especially with regards to the triploidy effect in woody perennials, to our knowledge, which has never been reported. Although the present materials and data were limited, the results offer a very significant clue for future exploration of the characteristics and function of DNA methylation in the polyploidization of different plant species, especially to further understand the molecular mechanisms of the triploidy effect in different plants and its relationship with the "odd-ploidy effect" first observed by Guo et al. (1996; Auger et al. 2005; Stupar et al. 2007).

Acknowledgments First, we thank the anonymous reviewers for critical reading of the manuscript and giving several constructive suggestions. We are also grateful to Dr. Dingliang Jiao, Tianjin Vegetable Research Institute, Tianjin, China; Dr. Chengquan Fang, Chinese Academy of Agricultural Sciences Fruit trees Research Institute, Liaoning, China; Dr. Liwang Qi, Chinese Academy of Forestry, Beijing, China; and Dr. Guolu Liang, Xinan University, Chongqin, China for kindly providing the materials of watermelon, Salvia, pear, Poplar, and loquat. This work was carried out with the financial support from The National Key Basic Research Program (N0. 2009CB119105) and the Doctoral Program of Higher Education of China for young teachers (N0. 20070055091), and The National Natural Science Foundation of China and Tianjin (N0. 30670211 and N0. 07JCYBJC11700).

Open Access This article is distributed under the terms of the Creative Commons Attribution Noncommercial License which permits any noncommercial use, distribution, and reproduction in any medium, provided the original author(s) and source are credited.

\section{References}

Adams KL, Wendel JF (2005) Polyploidy and genome evolution in plants. Curr Opin Plant Biol 8:135-141

Adams KL, Cronn R, Percifield R, Wendel JF (2003) Genes duplicated by polyploidy show unequal contributions to the transcriptome and organspecific reciprocal silencing. Proc Natl Acad Sci 100:4649-4654

Adams KL, Percifield R, Wendel JF (2004) Organ-specific silencing of duplicated genes in a newly synthesized cotton allotetraploid. Genetics 168:2217-2226

Albertin W, Brabant P, Catrice O, Eber F, Jenczewski E, Chèvre AM, Thiellement H (2005) Autopolyploidy in cabbage (Brassica oleracea L.) does not alter significantly the proteomes of green tissues. Proteomics 5:2131-2139

Auger DL, Gray AD, Ream TS, Kato A, Jrcoe EH, Birchler JA (2005) Nonadditive gene expression in diploid and triploid hybrids of maize. Genetics 169:389-397

Bhojwani SS, Razdan MK (1996) Plant tissue culture: theory and practice, a revised edition. Elsevier: Amsterdam pp 1-766

Blanc G, Barakat A, Guyot R, Cooke R, Delseny M (2000) Extensive duplication and reshuffling in the Arabidopsis genome. Plant Cell 12:1093-1101 
Cao X, Jacobsen SE (2002) Role of the Arabidopsis DRM methyltransferases in de novo DNA methylation and gene silencing. Curr Biol 12:1138-1144

Carvalho A, Polanco C, Lima-Brito J, Guedes-Pinto H (2010) Differential rRNA genes expression in hexaploid wheat related to NOR methylation. Plant Mol Biol Rep 28:403-412

Chen ZJ (2007) Genetic and epigenetic mechanisms for gene expression and phenotypic variation in plant polyploids. Annu Rev Plant Biol 58:377-406

Chen L, Chen J (2008) Changes of cytosine methylation induced by wide hybridization and allopolyploidy in Cucumis. Genome 51:789-799

Cuozzo C, Porcellii A, Angrisano T et al (2007) DNA damage, homology directed repair, and DNA methylation. PLoS Genet 3:110

Demetriou K, Kapazoglou A, Bladenopoulos K, Tsaftaris AS (2010) Epigenetic chromatin modifiers in barley: II. Characterization and expression analysis of the HDA1 family of barley histone deacetylases during development and in response to jasmonic acid. Plant Mol Biol Rep 28:9-21

Diéguez MJ, Bellotto M, Afsar K, Mittelsten SO, Paszkowski J (1997) Methylation of cytosines in nonconventional methylation acceptor sites can contribute to reduced gene expression. Mol Gen Genet 253:581-588

Fiuk A, Bednarek PT, Rybczyński JJ (2010) Flow Cytometry, HPLC-RP, and metAFLP analyses to assess genetic variability in somatic embryo-derived plantlets of Gentiana pannonica Scop. Plant Mol Biol Rep 28:413-420

Fortune PM, Schierenbeck KA, Ainouche AK, Jacquemin J, Wendel JF, Ainouche ML (2007) Evolutionary dynamics of Waxy and the origin of hexaploid Spartina species (Poaceae). Mol Phylogenet Evol 43:1040-1055

Gaeta RT, Pires JC, Iniguez-Luy F, Leon E, Osborn TC (2007) Genomic changes in resynthesized Brassica napus and their effect on gene expression and phenotype. Plant Cell 19:34033417

Gaut BS, Doebley JF (1997) DNA sequence evidence for the segmental allopolyploid origin of maize. Proc Natl Acad Sci 94:6808-6814

Guo M, Davis D, Birchler JA (1996) Dosage effects on gene expression in a maize ploidy series. Genetics 142:1349-1355

Hamada S (1963) Polyploid mulberry tree in practice. Indian J Ser $1: 3-4$

Han FP, Fedak G, Ouellet T, Liu B (2003) Rapid genomic changes in interspecific and intergenetic hybrids and allopolyploids of Triticeae. Genome 46:716-723

Hegarty MJ, Hiscock S (2007) Polyploidy: doubling up for evolutionary success. Curr Biol 17:927-929

Hilu KW (1993) Polyploidy and the evolution of domesticated plants. Am J Bot 80:1494-1499

Kashkush K, Feldman M, Levy AA (2002) Gene loss, silencing and activation in a newly synthesized wheat allotetraploid. Genetics 160:1651-1659

Keyte AL, Percifield R, Liu B, Wendel JF (2006) Intraspecific DNA methylation polymorphism in cotton (Gossypium hirsutum L.). J Hered 97:444-450

Lagercrantz U, Lydiate D (1996) Comparative genome mapping in Brassica. Genetics 144:1903-1910

Lee HS, Chen ZJ (2001) Protein-coding genes are epigenetically regulated in Arabidopsis polyploids. Proc Natl Acad Sci 98:6753-6758

Levy AA, Feldman M (2004) Genetic and epigenetic reprogramming of the wheat genome upon allopolyploidization. Biol J Linn Soc Lond 82:607-613

Liu B, Wendel JF (2002) Non-mendelian phenomena in allopolyploid genome evolution. Curr Genomics 3:489-505

Liu B, Wendel JF (2003) Epigenetic phenomena and the evolution of plant allopolyploids. Mol Phylogenet Evol 29:365-379
Liu B, Brubaker CL, Mergeai G, Cronn RC, Wendel JF (2001) Polyploid formation in cotton is not accompanied by rapid genomic changes. Genome 44:321-330

Lu BB, Pan XZ, Zhang L, Huang BB (2006) A genome-wide comparison of genes responsive to autopolyploidy in Isatis indigotica using Arabidopsis thaliana Affymetrix Genechips. Plant Mol Biol Rep 24:197-204

Lukens LN, Pires JC, Leon E, Vogelzang R, Oslach L, Osborn T (2006) Patterns of sequence loss and cytosine methylation within a population of newly resynthesized Brassica napus allopolyploids. Plant Physiol 140:336-348

Madlung A, Masuelli RW, Watson B, Reynolds SH, Davison J, Comai L (2002) Remodeling of DNA methylation and phenotypic and transcriptional changes in synthetic Arabidopsis allotetraploids. Plant Physiol 129:733-746

Martienssen RA, Colot V (2001) DNA methylation and epigenetic inheritance in plants and filamentous fungi. Science 293:1070 1073

Masterson J (1994) Stomatal size in fossil plants: evidence for polyploid in majority of angiosperms. Science 264:421-424

McClintock B (1984) The significance of responses of the genome to challenge. Science 226:792-801

Murray MG, Thompson WF (1980) Rapid isolation of high-weight plant DNA. Nucleic Acids Res 8:4231-4235

Osborn TC, Pires JC, Birchler JA, Auger DL, Chen ZJ, Lee HS, Comai L, Madlung A, Doerge RW, Colot V, Martienssen RA (2003) Understanding mechanisms of novel gene expression in polyploids. Trends Genet 19:141-147

Pires JC, Zhao JW, Schranz ME, Quijada PA, Lukens LN, Osborn TC (2004) Flowering time divergence and genomic rearrangements in resynthesized polyploids (Brassica ). Biol J Linn Soc Lond $82: 675-688$

Pontes O, Neves N, Silva M, Lewis MS, Madlung A, Comai L, Viegas W, Pikaard CS (2004) Chromosomal locus rearrangements are a rapid response to formation of the allotetraploid Arabidopsis suecica genome. Proc Natl Acad Sci 101:18240-18245

Portis E, Acquadro A, Comino C et al (2004) Analysis of DNA methylation during germination of peper (Capsicum annuum L.) seeds using methylation-sensitive amplification polymorphism (MSAP). Plant Sci 166:169-178

Rayburn AL, Crawford J, Rayburn CM, Juvik JA (2009) Genome size of three Miscanthus species. Plant Mol Biol Rep 27:184-188

Salmon A, Ainouche ML, Wendel JF (2005) Genetic and epigenetic consequences of recent hybridization and polyploidy in Spartina (Poaceae). Mol Ecol 14:1163-1175

Shaked H, Kashkush K, Ozkan H, Feldman M, Levy AA (2001) Sequence elimination and cytosine methylation are rapid and reproducible responses of the genome to wide hybridization and allopolyploidy in wheat. Plant Cell 13:1749-1759

Shoemaker RC, Polzin K, Labate J, Specht J, Brummer EC, Olson T, Young N, Concibido V, Wilcox J, Tamulonis JP, Kochert G, Boerma HR (1996) Gemome duplication in soybean (Glycine subgenus soja). Genetics 144:329-338

Soltis DE, Soltis PS, Tate JA (2004) Advances in the study of polyploidy since plant speciation. New Phytol 161:173-191

Song K, Lu P, Tang K, Osborn TC (1995) Rapid genome change in synthetic polyploids of Brassica and its implications for polyploid evolution. Proc Natl Acad Sci 92:7719-7723

Spring J (1997) Vertebrate evolution by interspecific hybridization: are we polyploid? FEBS Lett 400:2-8

Sreekumari MT, Jos JS, Nair SG (1999) 'Sree Harsha': a superior triploid hybrid in cassava. Euphytica 106:1-6

Stupar RM, Bhaskar PB, Yandell BS, Rensink WA, Hart AL, Ouyang S, Veilleux RE, Busse JS, Erhardt RJ, Buell CR, Jiang J (2007) Phenotypic and transcriptomic changes associated with potato autopolyploidization. Genetics 176:2055-2067 
Swapna M, Sivaraju K, Sharma RK, Singh NK, Mohapatra T (2010) Single-strand conformational polymorphism of EST-SSRs: a potential tool for diversity analysis and varietal identification in sugarcane. Plant Mol Biol Rep. doi:10.1007/s11105-0100254-5

Thomas TD, Bhatnagar AK, Bhojwani SS (2000) Production of triploid plants of mulberry (Morus alba L.) by endosperm culture. Plant Cell Rep 19:395-399

Udall JA, Quijada PA, Osborn TC (2005) Detection of chromosomal rearrangements derived from homeologous recombination in four mapping populations of Brassica napus L. Genetics 169:967979

Urdampilleta JD, Ferrucci MS, Torezan JMD, Vanzela ALL (2006) Karyotype relationships among four South American species of Urvillea (Sapindaceae: Paullinieae). Pl Syst Evol 258:8595

Wada Y, Miyamoto K, Kusano T, Sano H (2004) Association between up-regulation of stress-responsive genes and hypomethylation of genomic DNA in tobacco plants. Mol Gen Genomics 271:658666
Wang J, Tian L, Madlung A, Lee HS, Chen M, Lee JJ, Watson B, Kagochi T, Comai L, Chen ZJ (2004) Stochastic and epigenetic changes of gene expession in Arabidopsis polyploids. Genetics 167:1961-1973

Wang J, Tian L, Lee HS, Wei NE, Jiang H, Watson B, Madlung A, Osborn TC, Doerge RW, Comai L, Chen ZJ (2006) Genomewide nonadditive gene regulation in Arabidopsis allotetraploids. Genetics 172:507-517

Wolfe KH, Shields DC (1997) Molecular evidence for an ancient duplication of the entire yeast genome. Nature 387:708-713

Xiong LZ, Xu CG (1999) Patterns of cytosine methylation in an elite rice hybrid and its parentallines, detected by a methylationsensitive amplication polymorphism technique. Mol Gen Genet 261:439-446

Zhang HY, Peng H, Li Y, Xu PZ, Wang XD, Wu XJ (2006) Analysis of DNA cytosine methylation between haploid and its corresponding diploid rice. Chin Sci Bull 51:1529-1535

Zhao XX, Chai Y, Liu B (2007) Epigenetic inheritance and variation of DNA methylation level and pattern in maize intra-specific hybrids. Plant Sci 172:930-938 